\title{
Contribuição da etnometodologia para avaliação do cuidado de enfermagem no centro cirúrgico
}

\section{Contribution of ethnomethodology to evaluation of nursing care in the operating room \\ Contribución de la etnometodología para la evaluación de la atención de enfermería en el centro quirúrgico}

\author{
Lina Márcia Miguéis Berardinelli'; Mariana Nepomuceno Giron" ; Fátima Helena do Espírito Santo ${ }^{I I I}$
}

\begin{abstract}
RESUMO: A etnometodologia se caracteriza em compreender a realidade social de um determinado grupo ou instituição social. Para tanto, os objetivos deste estudo foram: caracterizar os discursos dos usuários do centro cirúrgico e analisar o cuidado de enfermagem evidenciado nesses discursos. Estudo etnometodológico, exploratório, desenvolvido com 18 usuários de um hospital estadual do Rio de Janeiro. Os dados foram coletados em 2013, por meio de observação participante e entrevista semiestruturada; em seguida, submetidos à análise de conteúdo, emergindo a categoria: Análise do cuidado de enfermagem no centro cirúrgico. O medo do desconhecido gerou desconforto, ansiedade e nervosismo nos usuários, reverberados nas falas, nos códigos, nos símbolos e no imaginário, que levam à profusão de ideias. Conclui-se que a etnometodologia contribui para a investigação dos fenômenos emergentes do cotidiano, viabilizando acesso às informações necessárias sobre o significado da experiência dos usuários, potencializando a subjetividade humana e as dimensões do cuidado, para o exercício de uma prática mais humanizada. Palavras-Chave: Cuidado; procedimento cirúrgico; etnometodologia; assistência de enfermagem.
\end{abstract}

\begin{abstract}
Ethnomethodology seeks to understand the social realities of a given social group or institution. This exploratory ethnomethodological study aimed to characterize the discourse of operating room users and analyze the nursing care evidenced by that discourse. Data were collected from 18 users at a state hospital in Rio de Janeiro in 2013 by participant observation and semi-structured interview. Content analysis revealed the category: analysis of nursing care in the operating room. Fear of the unknown generated user unease, anxiety and nervousness, which reverberated in the statements, codes, symbols, imagery, which lead to a profusion of ideas. It was concluded that ethnomethodology contributes to investigating everyday emergent phenomena, allowing access to the necessary information about the meaning of the user experience, and leveraging human subjectivity and the dimensions of care towards more humane care practices.
\end{abstract}

Keywords: Care; surgical procedure; ethnomethodology; nursing care.

RESUMEN: La etnometodología se caracteriza por comprender la realidad social de un determinado grupo social o institución. Para eso, los objetivos de este estudio fueron: caracterizar los discursos de los miembros de la sala de operaciones y examinar el cuidado de enfermería destacado en los discursos de los usuarios. Estudio exploratorio etnometodológico llevó a cabo con 18 miembros de un hospital del Estado de Río de Janeiro - Brasil. Los datos fueron recogidos en 2013, a través de observación participante y entrevista semiestructurada; después, fueron sometidos al análisis de contenido, emergiendo la categoría: Análisis de la atención de enfermería en la sala de operaciones. El miedo del desconocido ha generado malestar, ansiedad y nerviosismo en los usuarios, reverberados en las declaraciones, códigos, símbolos, imágenes que traen una gran cantidad de ideas. En conclusión, la etnometodología contribuye para la investigación de los fenómenos emergentes de la vida cotidiana, lo que permite el acceso a la información necesaria sobre el significado de la experiencia del usuario en la sala de operaciones que aprovechan la subjetividad humana y las dimensiones de la atención para ejercer una práctica más humana. Palabras Clave: Cuidado; acto quirúrgico; etnometodología; cuidados de enfermería quirúrgica.

\section{INTRODUÇÃO}

No início da tarde, por volta das $13 \mathrm{~h}$, no corredor interno de um setor hospitalar, havia uma pessoa deitada na maca, aguardando a sua vez para ser atendida. Ela vestia uma camisola azul e uma touca branca cobria seus cabelos. $\mathrm{O}$ rosto sem maquiagem mostrava poucas linhas de expressão e, pela aparência, era uma pessoa jovem. O olhar inquieto era de quem procurava alguma coisa, a testa franzida e os gestos de estalar os dedos das mãos marcavam o estado de apreensão e preocupação. $\mathrm{O}$ ambiente estava frio e

IEnfermeira. Professor Adjunto do Departamento de Enfermagem Médico-Cirúrgica e do Programa de Pós-Graduação da Faculdade de Enfermagem da Universidade do Estado do Rio de Janeiro. Brasil. E-mail: 1.m.b@uol.com.br

"Enfermeira da Secretaria Estadual de Saúde do Rio de Janeiro. Mestre pelo Programa de Pós-Graduação em Enfermagem da Faculdade de Enfermagem da Universidade do Estado do Rio de Janeiro. Brasil.E-mail: marigiron20@yahoo.com.br

IIIEnfermeira. Professor Associado do Departamento de Enfermagem Médico-Cirúrgica e do Programa de Pós-Graduação em Ciências do Cuidado em Saúde da Escola de Enfermagem Aurora de Afonso Costa de Universidade Federal Fluminense. Rio de Janeiro, Brasil. E-mail: fatahelen@terra.com.br

IV Recorte de Dissertação de Mestrado de: O acolhimento de usuários no centro cirúrgico e a humanização das práticas cotidianas do cuidado de enfermagem. Aprovada pelo Programa de Pós-Graduação em Enfermagem da Universidade do Estado do Rio de Janeiro, 2013. 
muitas pessoas circulavam pelo local, umas andavam rapidamente, outras passavam, olhavam e não diziam nada. Até que passou uma pessoa e disse: - Volto já para te buscar. E realmente voltou, após $35 \mathrm{~min}$.

Para cada leitor esta cena terá um sentido e um significado diferenciado. A cena descrita marca as características e a pluralidade da etnometodologia, a qual valoriza o sentido e o significado de uma determinada ação, definindo-se como análise de métodos e procedimentos utilizados pelos indivíduos para dar sentido às práticas sociais cotidianas ${ }^{1}$. Além disso, cumpre a função de analisar as crenças, os comportamentos de senso comum, as interações entre os membros do grupo, somando-se à prática social que leva também em conta o fato de todo o grupo social ser capaz de se compreender a si mesmo, comentar-se e analisar-se ${ }^{2}$. Considerando que a realidade é socialmente construída e está presente na vivência cotidiana de cada um, e que em todos os momentos podem-se compreender as construções sociais que permeiam as conversas, os gestos, a comunicação, isto é, as atividades práticas.

O local descrito pelo observador é um centro cirúrgico (CC), espaço de cuidado, de ensino e de pesquisa, complexo, em função das especificidades tanto por atender o ser humano em situação cirúrgica em busca de solução para seu problema de saúde-, quanto ao ambiente, o qual se diferencia dos demais espaços do hospital, seja pela restrição de acesso, seja pela presença de diferentes aparatos tecnológicos, cirúrgicos, medicações, drogas anestésicas e aparelhos de monitorização ${ }^{3}$.

Nesse ambiente a enfermagem é responsável pela recepção e acolhimento dos pacientes que necessitam de cuidado especial em função da dependência de um procedimento cirúrgico, como também é responsável pela gerência e administração da unidade e das equipes de enfermagem ${ }^{4}$.

Além disso, as ações de cuidados estão em constante avaliação, tanto das equipes multiprofissionais como dos usuários, tendo em vista que o centro cirúrgico consiste em um ambiente suscetível aos mais variados riscos para os profissionais lá inseridos e é visto como um ambiente altamente estressante para o paciente e a equipe de trabalho.

Somando-se a isto, os profissionais de enfermagem, ao longo da trajetória histórica, vêm desenvolvendo suas atividades de maneira mecanizada, repetitiva e controladora, alicerçada em normas, rotinas e protocolos, na maioria das vezes, sem reflexão de sua prática $^{5}$ e sem a leitura da subjetividade humana, tão necessárias para compreensão do indivíduo, como ser humano e como um ser de sensibilidade. Portanto, entendendo o ser humano, como um ser único, multidimensional, impregnado de história, merece ser visto individualmente, ajudando-o refletir sobre seus conflitos, suas relações com o mundo, com a família, com o trabalho, bem como, em interação com o outro, para formação de vínculo, realização do cuidado e com a capacidade de conduzir seu próprio destino.

Nesse sentido, contrariando o contexto descrito anteriormente, quem sofre com as repercussões são os usuários das instituições de saúde, os quais deixam de receber o cuidado, carinhoso e digno de seus desejos e necessidades. E, dessa maneira, ocorrem os descontentamentos e críticas em relação ao cuidado de enfermagem oferecido.

A experiência da escuta ativa e relatos das expectativas dos usuários foram suficientes para analisar as repercussões dos descontentamentos, dos medos, das angústias e anseios em relação ao CC, bem como, o atendimento pelas equipes. Esse canal de diálogo com os usuários fortaleceram nossas habilidades cognitivas, afetivas e emocionais de modo a favorecer a atenção e sensibilidade às demandas daquelas pessoas, sendo decisivo o desenvolvimento deste estudo.

Assim, observou-se que após a alta hospitalar alguns usuários retornavam para consulta e comentavam sobre o atendimento oferecido. $\bigcirc$ mesmo fato também observado no CC: após alta para enfermaria clínica e/ou alta hospitalar, os usuários expressavam seus sentimentos em relação à assistência de enfermagem recebida naquela unidade. Durante esta vivência profissional com esse tipo de clientela, foi possível entender melhor o quanto é difícil para as pessoas lidar com situações cirúrgicas, agudas ou de emergência, pois, além dos sentimentos de medo e insegurança, há também alteração da autoestima, ansiedade e, muitas vezes, frustração.

Por outro lado, a literatura de enfermagem no centro cirúrgico contextualiza a humanização da assistência à saúde, perpassando pela história da profissão, a humanização do enfermeiro, seus múltiplos discursos até a Política Nacional de Humanização $0^{6-10}$. Os diferentes enfoques sobre a humanização no centro cirúrgico analisam o cuidado de enfermagem oferecido aos usuários que necessitam resolver seus problemas de saúde.

A partir do exposto, surge a seguinte questão: como se dá a contribuição da etnometodologia na avaliação do cuidado de enfermagem pelos usuários do centro cirúrgico? Para tanto, foram estabelecidos os seguintes objetivos: caracterizar os discursos dos usuários do centro cirúrgico e analisar o cuidado de enfermagem evidenciado nesses discursos.

Esse estudo poderá contribuir para subsidiar os enfermeiros que atuam no CC, em suas relações com os usuários nos períodos pré, trans e pós-operatórios, tanto os que atuam na prática assistencial quanto na gerência da unidade. Da mesma forma, suscitar reflexões, criando estratégias de cuidado em conjunto com a equipe, de maneira com que as pessoas se sintam bem atendidas, vencendo os impactos causadores de reações e sentimentos negativos que levam à ansiedade, medo e estresse. 


\section{Referencial TeóRICO-Metodológico}

A etnometodologia é uma corrente social originada no âmbito da Sociologia americana, a partir dos estudos de Harold Garfinkel, especificamente na obra Studies in Ethnomethodology, em $1967^{11}$.

Considera que a realidade é socialmente construída por seus membros, a partir do conhecimento prático de um determinado grupo sobre suas atividades diárias, por meio de conversa, gestos e comunicação, os quais dão sentido às suas ações cotidianas.

Essa corrente tem também suas origens ligadas à etnografia, ao interacionismo simbólico, ao existencialismo, ao marxismo e à fenomenologia de Alfred Schütz. Caracteriza-se como um método indutivo e visa a documentar, descrever, explicar e interpretar a visão de mundo, significados, símbolos e experiência de vida dos sujeitos participantes ${ }^{12}$.

A importância teórica e epistemológica da etnometodologia é devida ao fato de efetuar uma ruptura radical com modos de pensar da sociologia tradicional. Enquanto a sociologia de cunho positivista encarava os fenômenos sociais como realidades objetivas, a etnometodologia buscava compreendê-los como construções práticas do próprio indivíduo.

Dessa maneira, o fato social deixa de ser objeto estável para ser produto da atividade contínua dos homens, que passam a ser encarados como atores. A nova corrente teórica, então, passa a dar importância e analisar as atividades cotidianas como se fossem métodos que os membros da sociedade utilizam para tornar essas atividades racionais. Desde o seu início, Garfinkel utilizou termos considerados conceitoschave da etnometodologia, como: prática, indicialidade, reflexividade e noção de membro ${ }^{13}$.

\section{Método}

Estudo descritivo exploratório, fundamentado nos princípios etnometodológicos, foi desenvolvido em um hospital estadual no período de maio/julho de 2013. É considerado um hospital de urgência e emergência de media e alta complexidade, pertencente à Rede da Secretária Estadual de Saúde do Rio de Janeiro e localizado no município de São Gonçalo. Os sujeitos da pesquisa foram constituídos por 18 usuários em pós-operatório, internados nas unidades de clinica médica e clinica cirúrgica do referido hospital.

Os critérios adotados para inclusão foram: adultos com idade igual ou superior a 18 anos, sem distinção de sexo, raça, cor e religião; após serem submetidos a procedimentos cirúrgicos, independente da natureza do procedimento, emergencial ou eletivo; estar em condições clínicas favoráveis, lúcidos e orientados; interessados em participar de todas as etapas de desenvolvimento da pesquisa de forma voluntária.
Esta pesquisa foi realizada atendendo ao disposto na Resolução no 466/2012 do Conselho Nacional de Saúde, sobre pesquisas envolvendo seres humanos, sob o protocolo $n^{\circ} 276.54$. A participação dos pacientes no estudo se condicionou à assinatura do Termo de Consentimento Livre e Esclarecido, após a leitura e compreensão dos procedimentos éticos sobre o anonimato, os objetivos, as vantagens e desvantagens quanto à implementação da pesquisa.

Os dados foram produzidos por meio da observação participante, registrados no diário de campo e pela entrevista semiestruturada, individual, com questões específicas ao estudo, gravadas em aparelho eletrônico MP3, apoiada por um roteiro previamente testado. Portanto, intercalamos os dados do diário de campo com as entrevistas. Os participantes foram identificados com a letra $\mathrm{P}$ associada ao número sequencial de participação, exemplificando: P1, P2, P3 e assim sucessivamente.

Após a entrevista, os dados foram transcritos, organizados, distribuídos cronologicamente de acordo com as respostas, classificados e categorizados, segundo o método da análise de conteúdo ${ }^{14}$, emergindo três categorias, das quais apenas uma será tratada neste estudo: Avaliação do cuidado de enfermagem no centro cirúrgico.

\section{Resultados e Discussão}

Os 18 usuários participantes do estudo submetidos a procedimentos cirúrgicos encontravam-se na faixa etária entre 25 a 84 anos, sendo que a maioria com idade maior que 55 anos; prevaleceram o sexo masculino e a cor da pele branca. A renda familiar relatada compreende entre 2 e 3 salários mínimos.

Em relação à observação participante, foi selecionada uma situação cena do diário de campo, conforme as anotações a seguir:

Situação: Em uma 4af., às 13:30h um senhor, adulto, internado na unidade, aguardava para ser reoperado de uma cirurgia eletiva da ortopedia. Deu entrada no CC, em maca, conduzido pelo maqueiro e acompanhado por uma técnica de enfermagem. O paciente foi recebido pelo enfermeiro do setor na porta do CC que o conduziu para dentro. O profissional esteve o tempo todo calado, no entanto, o paciente aparentemente ansioso, desde o momento em que entrou no CC não hesitava em falar, na tentativa de uma interação como profissional, para explicar que ele estava ali para uma reoperação cirúrgica. Durante as falas do usuário, o enfermeiro sorria enquanto conduzia a maca. Quando o usuário parou de falar, o enfermeiro perguntou sobre comorbidades e alergias, tendo respostas negativas para ambas. O profissional manteve o paciente aguardando o procedimento na maca, parado no corredor do CC.

A situação descrita demonstra indícios da construção da realidade e práticas sociais que acontecem 
no CC. Percebe-se que em alguns momentos, a interação entre profissional e usuário é restrita, com pouca comunicação verbal. Contudo, em outro momento, foi observado que a interação entre os usuários e os profissionais perpassa pela comunicação não verbal presente no contato humano, em estar ao lado, prestar atenção ao que o usuário manifesta nesse instante.

A comunicação, que pode ser verbal e não verbal, é que promove um envolvimento, um vínculo e, consequentemente, o estabelecimento de uma relação de confiança entre o usuário e o profissional; caracteriza-se como uma forma pensante, atuante, desejosa, carregada de subjetividades capazes de superar as barreiras físicas que separam as pessoas, o ambiente interno do CC e o externo ${ }^{15}$.

Identifica-se que, ao entrar no CC, o paciente está apreensivo e entrega a sua situação de saúde para alguém que não conhece para que seu problema seja solucionado.

O enfermeiro é o profissional que produz um território vivo e comum no cotidiano de sua prática e pode proporcionar flexibilização nas suas tarefas no intuito de responder às demandas dos usuários. Assim, há de se estabelecer uma comunicação verbal ou não verbal. A comunicação verbal envolve o diálogo, ouvir o que o usuário tem a dizer nesse momento, o que conduzirá a sua prática de cuidado em relação a esse indivíduo.

Sob este argumento, a escuta atentiva é um elemento da comunicação que está presente no processo de cuidar, e é nesse momento que as formas de cuidado passam a ser desenvolvidas de acordo com as relações que se travam durante o encontro entre duas pessoas livres, de consciência e universos culturais diferentes. E valorizando esse espaço de encontro, de conhecimento entre duas pessoas, é que os laços de amizade e de confiança profissional vão se constituindo. Favorecer esse espaço de diálogo é humanizar o cuidado ${ }^{16}$. Sequencialmente, apresentam-se os resultados da categoria.

\section{Avaliação do cuidado de enfermagem no centro cirúrgico}

Nesta categoria, a realidade social construída no CC se constitui através da linguagem, não a usada da gramática e da linguística, mas a da vida cotidiana no CC, como pode ser constatado nos seguintes discursos:

O pessoal é muito bom. A minha frustração é porque o que move, é a motivação para essas pessoas continuarem trabalhando. Para ser enfermeiro, para trabalhar na área da saúde, você tem que ter um DNA para isso, você tem que gostar do que você faz. (P12)

As enfermeiras sempre me tratam bem, até na hora quando acaba a cirurgia me chamam, mudam da cama, me levam para lá [Unidade de Recuperação Pós
Anestésica - URPA], fica sempre verificando se eu estou bem, se já estou melhorando, se estou acordando. Mas assim, eu não tenho nada do que reclamar. (P1)

Foi ótimo, o tempo todo tentando me tranquilizar [...] ela [enfermeira] entrou umas três vezes [na URPA] para conversar com a gente. (P2)

Cheguei lá [no CC], inclusive não era dia de visita, meu filho estava preocupado que ele não sabia onde eu estava. A enfermeira fez questão de me tirar de lá [URPA], levou-me lá fora para o meu filho me ver na porta do CC; trouxe-me de volta, me tratou bem, toda hora vendo o que eu precisava. Arrumou uma enfermaria para mim e falou que ia lá, se eu tivesse, aqui, quinta feira, me ver. Para mim, nota mil. (P3)

Olha, eu não sei nem se é certo eu falar isso, [...] elas mereciam ganhar um pouco mais pelo que elas fazem ali, entendeu. Eu acho que deveria ser mais valorizado o trabalho delas. (P4)

A expressão indicialidade, entendida como o conjunto de linguagens, foi transposta pela Etnomedologia ${ }^{17}$ e encontra-se presente nas entrelinhas dos depoimentos. De certa maneira evidenciada no julgamento das ações de cuidado. Segundo a percepção dos depoentes, os trabalhadores de enfermagem são bons. Eles conseguiram demonstrar porque escolheram essa profissão, pois, segundo o entendimento de alguns, mesmo com a desvalorização do trabalho, a enfermagem, expressa compromisso ao longo do desenvolvimento de suas atividades. Notadamente a avaliação do cuidado aparece em todas as formas simbólicas conforme enunciadas nos depoimentos, assim como as regras, o gestual, e o comportamento.

foco da Etnometodologia tem suas lentes voltadas para as questões conceituais como tópicos fundamentais da sociologia, para a teoria da ação, para a natureza da intersubjetividade e finalmente para a constituição social do conhecimento ${ }^{18}$.

Observa-se igualmente entre outros autores, que os agentes sociais buscam a exploração das propriedades do raciocínio prático e das ações práticas, analisam as suas circunstâncias e as influências, compartilham uma compreensão subjetiva dessas mesmas circunstâncias, apontando para as compreensões corriqueiras e avaliação das maneiras complexas e pormenorizadas pelas quais os contextos fornecem subsídios para a sua interpretação ${ }^{17}$.

Nesse sentido, é possível entender, se o cuidado de enfermagem implica realizações de ações em prol da vida, alicerçadas na satisfação das necessidades tanto dos usuários quanto dos profissionais dos serviços que promovem o cuidado, o qual precisa envolver interação, autonomia e resolutividade dos sujeitos envolvidos.

Os participantes continuaram a relatar o que poderia ser melhorado no cuidado de enfermagem no CC: 
Conversar mais com a gente, saber acalmar. Tem hora que a gente chega tão nervosa, [...] tem pacientes que saem daqui com a pressão ótima e voltam dizendo que não operou porque a pressão subiu, entendeu? Então acho que é acalmar, porque a gente entra lá, num ambiente que assusta. (P1)

Eu acho que é [... de esperar, ter que ficar ali [URPA]. Porque, eu estava nervoso, às vezes passava uma pessoa e eu ficava chamando, entendeu? [...] outras vezes não dava para escutar. Eu achava que tinha que ficar uma pessoa ali, as pessoas estão no soro. Assim, uma pessoa para atender ali, pelo menos para dar mais atenção [...] eu fiquei nessa sala aí umas duas ou três horas antes de eu ir para a cirurgia, no aguardo. Estava tendo várias cirurgias. (P2)

Falta mais carinho pelos pacientes. Não te conheço, mas também me aconchega, eu estou num momento difícil. Não te conheço, nunca te vi, estou ali, vamos embora, brincando, descontraiu, mas o carinho: Tenha calma, vai ficar tudo bem, fica tranquilo, essa força. Ajuda, um: Oi, tudo bom? Você vai operar agora. Uma conversa, sabe? Brincou, foi bom, distraiu bastante, mas um carinho que a gente precisa dos nossos pais nessa hora, eles podiam ser, no meu ponto de vista. Não fui maltratado em momento algum, mas para deixar o paciente mais tranquilo. Apesar de ter passado por isso pela primeira vez, a primeira impressão é a que fica. Fui tratado bem e tal, mas é só um carinho a mais [...]. (P14)

Nos depoimentos, observa-se o conceito de reflexividade, um etnométodo que designa as práticas que ao mesmo tempo descrevem e constituem o quadro social regido pelos códigos e comportamentos do grupo ${ }^{18}$. Como observado pelos usuários, ao mencionaram a necessidade da presença de um profissional da enfermagem à beira do leito, de alguém que esteja perto. É preciso compreender que estar ao lado, dando apoio e conforto ao usuário, também é cuidado de enfermagem e esse aspecto é muito pouco valorizado e, muitas vezes, visto como uma ação de menor importância. Apesar de julgarem o trabalho oferecido pelos profissionais de enfermagem como muito bom, ainda assim, alguns usuários relataram que falta interação, comunicação, mais conversa entre os profissionais de enfermagem e o usuário, o que demonstra que a formação de vínculo e a presença são fundamentais nesse momento em que o indivíduo se encontra fragilizado, em um espaço físico geralmente incomum a ele e com uma gama de sentimentos e expectativas em relação ao ato cirúrgico. Além disso, acrescenta-se que essas ações são descritíveis, relatáveis inteligíveis e analisáveis, conforme desenvolvido também nos trabalhos apresentados pelas autoras ${ }^{19-23}$. E, assim, a Etnometodologia se preocupa em elucidar como os relatos ou as descrições de um acontecimento são produzidos em interação, de modo a atingir um estatuto metodológico claro e objetivo.

\section{CONClusão}

Neste estudo, foi possível caracterizar os discursos dos usuários do centro cirúrgico e analisar o cuidado de enfermagem evidenciado a partir desses pronunciamentos. Analisar os cuidados de enfermagem no CC depende sempre do foco e do ângulo de visão que se deseja alcançar, tendo em vista os avanços tecnológicos dos aparelhos utilizados, do tipo de cirurgia, cujo porte determina a complexidade ou não do cuidado. A vulnerabilidade do paciente cirúrgico exige do enfermeiro, nessa área, atuação respaldada em conhecimentos específicos dos períodos pré, trans e pós-operatório para o alcance dos objetivos, sucesso terapêutico e segurança do ato cirúrgico e do cuidado.

Buscou-se o foco da Etnometodologia para a descrição e ampliação do fenômeno pesquisado, como contribuição para a análise do cuidado de enfermagem, a partir dos discursos dos usuários que realizaram procedimentos cirúrgicos e isso somente foi possível, pela disponibilidade e troca de experiências dos usuários que utilizaram os serviços do centro cirúrgico..

O cuidado de enfermagem no CC, conforme observado nos depoimentos, recaiu para a subjetividade, ou seja, o usuário sentiu falta do que é essencial no cuidado humano, da escuta atentiva, do carinho, da atenção, da solidariedade na chegada ao centro cirúrgico e de ser acolhido nas suas demandas de saúde.

O CC como uma unidade peculiar e complexa dentro do contexto hospitalar, cujas especificidades, muitas vezes, passam despercebidas para quem não conhece e se transforma em um local temido por todos, principalmente para quem nunca precisou de uma intervenção cirúrgica. $\mathrm{O}$ medo do desconhecido gera desconforto, ansiedade e nervosismo, por parte dos usuários, reverberado nas falas, nos códigos verbais e não verbal, nos símbolos, no imaginário, que levam a uma profusão de ideias. De igual maneira, observado na gestualidade dos profissionais e equipes de saúde, os quais desavisadamente, ao desenvolverem suas atividades, emitem sinais e informações que são assustadoras para quem aguarda um procedimento. Sobretudo, diante da rotina diária de um CC, cujas atividades já se tornaram banais e corriqueiras, para certos profissionais, que deixaram de considerar os requisitos mínimos de atenção e cuidado com quem está fragilizado em sua saúde.

Mesmo assim, é comum que os pacientes se surpreendam quando são bem tratados, em função de experiências prévias de descuidado ou de descaso das instituições públicas, de profissionais e serviços de saúde, quando na verdade o ser humano é o foco da assistência de qualquer profissional de saúde comprometido com a sua prática.

Conclui-se que a Etnometodologia contribui para a investigação dos fenômenos emergentes do 
cotidiano, viabilizando informações necessárias e conhecimento que potencializam a subjetividade humana e as dimensões do cuidado, para o exercício de uma prática mais humanizada.

\section{REFERÊNCIAS}

1.Coulon A. La etnometodología. Madrid (Es): Ediciones Cátedra; 2005.

2.Coulon A. Etnometodologia. Petrópolis (RJ), Vozes; 1995. 3.Giron MN. O acolhimento de usuários no centro cirurgico e a humanização das práticas cotidianas do cuidado de enfermagem [dissertação de mestrado]. Rio de Janeiro: Universidade do Estado do Rio de Janeiro; 2013.

4.Silvia DC, Alvim NAT. Ambiente do centro cirúrgico e os elementos que o integram: implicações para os cuidados de enfermagem. Rev bras enferm. 2010; 63: 427-34. 5.Regis LFLV, Porto IS. Necessidades humanas básicas dos profissionais de enfermagem: situações de (in) satisfação no trabalho. Rev esc enferm USP. 2011;45:334-41. 6.Oliveira BRG, Collet N, Viera CS. A humanização na assistência à saúde. Rev Latino-Am Enfermagem. 2006; 14: 277-84.

7.Ministério da Saúde (Br). Política nacional de humanização: humaniza SUS: Brasília (DF): Editora MS; 2004 8.Ministério da Saúde (Br). Cadernos humanizaSUS: atenção hospitalar. Brasília (DF): Editora MS; 2011.

9.Macedo CA, Teixeira ER, Daher DV. Possibilidades e limites do acolhimento na percepção de usuários. Rev enferm UERJ. 2011; 20: 457-62.

10.Giron, MN, Berardinelli LMM, Santo FHE. O acolhimento no centro cirúrgico na perspectiva do usuário e a política nacional de humanização. Rev enferm UERJ. 2013; 21: 766-71.

11.Rawls AW. Harold Garfinkel, ethnomethodology and workplace studies. Bentley College (USA): Organization Studies; 2008.
12.Maciel LHR, Lima Junior PO, Capelle MAC. Etnometodologia: uma revisão sistemática sobre o tema em bases de dados da Web. Revista FSA. (Teresina) 2014; 11:70-83.

13. Berardinelli LMM. A (im) posição silenciosa no cotidiano da enfermeira preceptora [dissertação de mestrado]. Rio de Janeiro: Universidade Federal do Rio de Janeiro, 1998.

14.Bardin L. Análise de conteúdo. Lisboa (Pt): Edições 70; 2009

15.Waldol VR. Cuidar: expressão humanizadora da enfermagem. Petrópolis (RJ): Vozes; 2006.

16. Waldol VR, Fensterseifer M. Saberes da enfermagem: a solidariedade como uma categoria essencial do cuidado. Esc Anna Nery. 2011; 15: 629-32.

17. Oliveira AS, Montenegro LM. Etnometodologia: desvelando a alquimia da vivência cotidiana. Cadernos EBAPE.BR. 2012; 10 (1):129-45.

18.Guidens A, Turner J. Teoria social hoje. Tradução de Gilson C. de Souza. São Paulo: UNESP; 1999.

19.Vargha Z. Organization, interaction and practice: studies of ethnomethodology and conversation analysis. Organization Studies. 2011; 32:1745-9.

20.Coelho MJ. Cuidar/cuidados em enfermagem de emergência: especificidade, aspectos distintivos no cotidiano assistencial [tese de doutorado]. Rio de Janeiro: Universidade Federal do Rio de Janeiro; 1997.

21.Santo FHE. As interações entre profissionais e estudantes na trama da construção da identidade profissional da enfermeira [dissertação de mestrado]. Rio de Janeiro: Universidade Federal do Rio de Janeiro;1997. 22.Santo FHE. Saberes e fazeres de enfermeiras (os) novatas (os) e veteranas (os) sobre o cuidado de enfermagem no cenário hospitalar [tese de doutorado]. Rio de Janeiro: Universidade Federal do Rio de Janeiro; 2003. 23.Berardinelli LMM Gestos de Cuidado: Estudo Interdisciplinar através de Imagens. [tese de doutorado]. Rio de Janeiro: Universidade Federal do Rio de Janeiro; 2003. 